may be that the time between the application of the lignocaine ointment and heel lance was insufficient to allow the full anaesthetic effect to occur in this study. This could be addressed by comparing the behavioural response of infants who had received topical lignocaine ointment for different lengths of time before heel lance. Another explanation is that the behavioural responses used in this study are insensitive when used to assess acute pain. This point emphasises the need for further evaluation of methods of assessing acute pain in infants.

1 Steward DJ. Eutretic mixture of local anaesthetics (EMLA): What is it? What does it do? 7 Pediatr 1993; 122: s21-3.
2 Koren G. Use of the eutretic mixture of local anaesthetics in young children for procedure related pain. $\mathcal{F}$ Pediatr 1993 122: $\mathrm{s} 30-5$.

3 Enberg G, Danielson K, Henneberg S, Nilsson A. Plasma concentrations of prilocaine and lidocaine and methaemoglobin formation in infants after epicutaneous application of a 5\% lidocaine-prilocaine cream (EMLA). Acta Anaesthesiol Scand 1987; 31: 624-8.

4 Jakobson B, Nilsson A. Methaemoglobinaemia associated with a prilocaine-lidocaine cream and trimethoprimwith a prilocaine-lidocaine cream and trimethoprim1985; 29: 453-5.

5 Nilsson A, Engberg G, Hennerberg S, Danielson K, de Verdier C-H. Inverse relationship between age dependent erythrocyte activity of methaemoglobin reductase and prilocaine-induced methaemoglobinaemia during infancy. Br f Anaesthes 1990; 64: 72-6.

6 Rushforth JA, Levene MI. Behavioural response to pain in healthy neonates. Arch Dis Child 1994; 70: F174-6.

7 Prechtl HFR. The behavioural states of the newborn infant (a review). Brain Res 1974; 76: 185-212.

8 Wester U. Analgesic effect of lidocaine ointment on intact skin in neonates. Acta Paediatr 1993; 82: 791.

\title{
Atrioventricular block during fetal heart rate decelerations
}

\author{
Michele P Mohajer, Daljit S Sahota, Nicholas N Reed, David K James
}

\begin{abstract}
Electrocardiograms (ECG) was examined in 15 fetuses during fetal heart rate decelerations in labour. Sinus bradycardia was demonstrated in six cases and in two cases inversion of the $P$ wave was seen. In seven cases there was complete dissociation of the $P$ wave from the QRS complex, indicating complete atrioventricular heart block.

Many decelerations are vagally mediated, but such cases associated with complete atrioventricular heart block may be due to the effect of hypoxia on the bundle of His.
\end{abstract}

(Arch Dis Child 1995; 72: F51-F53)

Keywords: atrioventricular block, fetal heart rate, deceleration.
Fetal heart rate decelerations have been the subject of obstetric concern for over a century. ${ }^{1}$ Attempts have been made to classify heart rate patterns, and to understand the pathogenesis of fetal heart rate decelerations. ${ }^{2}$ Changes in fetal heart rate are a function of many factors, and the pathophysiological mechanisms are not fully understood. In most cases the fall in heart rate is thought to be vagally mediated, either by head compression or by stimulation of the fetal umbilical cord, or by chemoreceptor response to hypoxia. ${ }^{2}$ If these changes are attributable to vagal stimulation then direct examination of the fetal electrocardiogram (ECG) should reveal sinus bradycardia, or configurational changes in the $P$ wave of the electrocardiogram could imply a wandering pacemaker. ${ }^{3}$ The aim of this study was therefore to make a direct examination of the fetal ECG during fetal heart rate decelerations in labour to clarify the underlying pathophysiology.

\section{Methods}

Women in labour were selected for monitoring preferentially on the basis of a fetal risk factor (table). The fetal ECG signal was obtained

Risk factors in study population

\begin{tabular}{|c|c|}
\hline Risk factor & $\begin{array}{l}\text { No of } \\
\text { patients }\end{array}$ \\
\hline Pregnancy induced hypertension & 14 \\
\hline Postmaturity & 10 \\
\hline Antepartum haemorrhage & 5 \\
\hline Diabetes & 4 \\
\hline Intrauterine growth retardation & 12 \\
\hline $\begin{array}{l}\text { Intrapartum problems (abnormal CTG, meconium, } \\
\text { delay in first stage) }\end{array}$ & 21 \\
\hline $\begin{array}{l}\text { Social factors (teenage mother, heavy smoking of } \\
>20 / \text { day, late booker) }\end{array}$ & 16 \\
\hline Epilepsy & 1 \\
\hline Thyroid disease & 2 \\
\hline
\end{tabular}


A

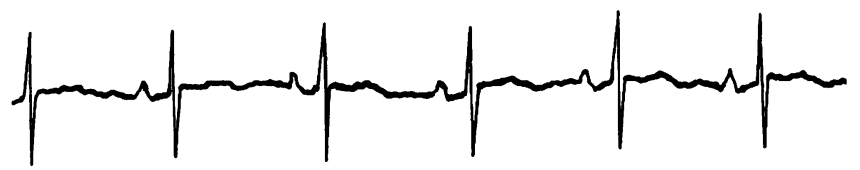

ECG recorded at conventional rate of 5 divisions/sec

B
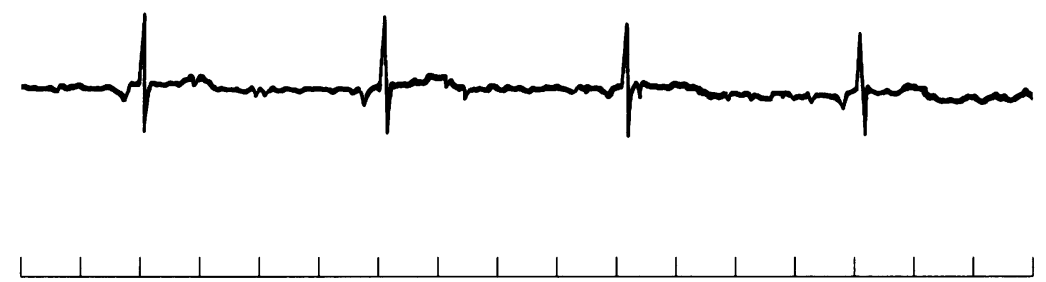

ECG recorded at conventional rate of 5 divisions/sec

Figure 2 (A) Raw FECG signal showing sinus rhythm during normal heart rate. (B) Segment of raw FECG showing $P$ wave inversion during a prolonged period of bradycardia.

using a conventional Copeland scalp electrode (Surgicraft) applied to the presenting part of the fetus. The signal was fed into a modified Sonicaid FM3R fetal monitor which provided a cardiotocograph (CTG) record for the labour ward staff. The FM3R monitor was modified to restore the low frequency components of the fetal ECG and to permit a fetal ECG signal of

A
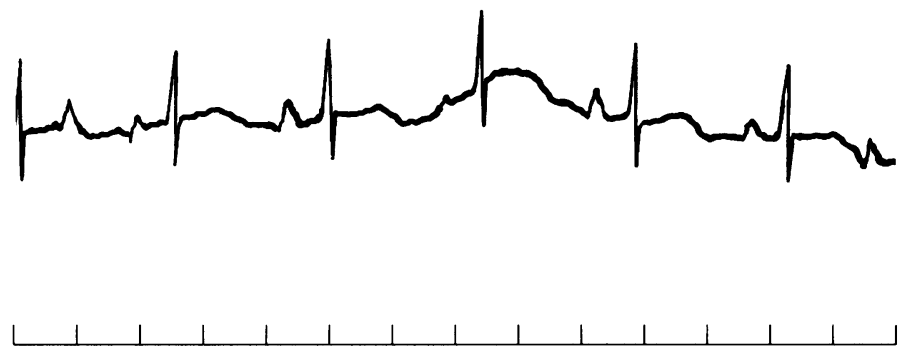

ECG recorded at conventional rate of 5 divisions/sec

B
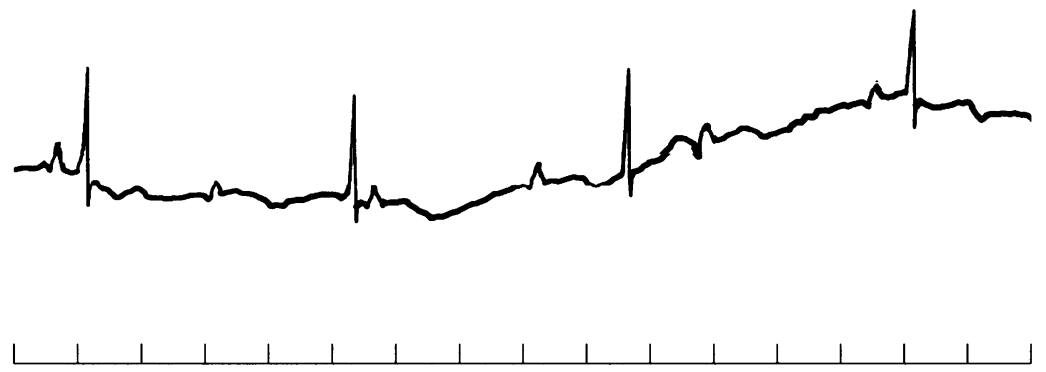

ECG recorded at conventional rate of 5 divisions/sec

Figure 3 (A) Raw FECG signal showing sinus rhythm during normal heart rate. (B) Raw FECG showing complete atrioventricular block during a severe deceleration. bandwidth $0 \cdot 16 \mathrm{~Hz}$ to $500 \mathrm{~Hz}$. The signal was recorded onto tape using a RACAL Store 4 FM recorder for retrospective analysis.

The recorded signal was replayed directly through a CTG monitor and an ECG recorder. Decelerations were identified using the CTG trace and ECG strips were then printed immediately before, during, and after the heart rate decelerations.

\section{Results}

A total of 132 fetuses were monitored in this study (3.8\% of total deliveries). Of these, 52 ( $1.5 \%$ of total deliveries) demonstrated clear fetal heart rate decelerations. However, only 15 of these were of sufficient quality for the retrospective examination of the raw ECG signal.

In these 15 fetuses two patterns of ECG response were observed. During moderate falls in the fetal heart rate, which occurred in eight of these fetuses (fetal heart rate falling to no less than 80 beats a minute), the ECG was clearly identified as sinus rhythm - that is, a sinus bradycardia (fig 1). In six of these fetuses the fetal heart rate decelerations were classified as mild or moderate variable decelerations. In the other two fetuses the fall in heart rate was prolonged for more than six minutes, and in these cases the $P$ wave inverted during the bradycardic period (fig 2). In all the remaining seven fetuses when the heart rate fell to 60 beats a minute (or less), the $\mathbf{P}$ wave became completely dissociated from the QRS complex of the ECG, demonstrating complete atrioventricular heart block (fig 3). In six cases the decelerations were classified as severe variable decelerations, two cases of which were atypical. One case showed a prolonged period of bradycardia of 60 beats a minute for eight minutes. In all cases, as the heart rate increased, sinus rhythm eventually returned.

\section{Discussion}

The control of the fetal heart rate is complex. The most common cause of irregularity of the fetal heart rate during labour has been termed variable deceleration due to compression of the umbilical cord. It has been suggested that most of these heart rate patterns may be largely due to vagal cardiovascular reflex activity rather than primary hypoxia. ${ }^{2}$ Based on this assumption, other researchers have attempted to confirm the vagal influence by the administration of vagal blocking agents, with variable success. ${ }^{45}$

Atrioventricular heart block has been observed in asphyxiated fetal calves and baboons following artificial occlusion of the umbilical cord. ${ }^{56}$ Clinical studies on the human fetus have been unable to demonstrate complete heart block, and observation of the fetal ECG during decelerative heart rate patterns has shown apparently absent or biphasic $P$ waves. ${ }^{34}$ However, the methods in both these studies relied on group averaging of up to 30 ECG complexes. Group averaging 
could obliterate transient configurational changes in the fetal ECG. In our study only the raw fetal ECG signal was examined, without the assistance of computer averaging techniques. Although this allowed the observation of transient configurational changes to be seen, many signals were unsatisfactory for analysis due to electrical noise interference. Vagal mechanisms are clearly involved in the production of sinus bradycardias and a change in pacemaker site. Excessive vagal activity may completely block the sinoatrial node producing the sick sinus syndrome. Complete atrioventricular block implies an interruption in the myocardial conduction system between the sinoatrial node (SAN) and the atrioventricular node (AVN). This is unlikely to be caused by a vagal mechanism, but rather, cellular hypoxia along the His bundle, an area of the conduction system known to be very sensitive to hypoxia. ${ }^{7}$ Both the SAN and AVN are resistant to hypoxia and will continue to fire action potentials, albeit independently, despite low levels of oxygen. ${ }^{7}$

Severe variable decelerations of the fetal heart rate have been more often associated with abnormalities of fetal acid base, ${ }^{8}$ as have absolute degrees of deceleration, ${ }^{9}$ which would support this phenomenon of atrioventricular heart block.

Techniques which permit accurate evaluation of the fetal ECG during labour may assist in the differentiation between bradycardias caused by vagal reflex activity and the more sinister conduction defects attributable to asphyxia.

1 von Winckel F. Lehrbuch der Geburtshulfe einschliesslich der Pathologie und Therapie des Wochenbetts. Fur praktische Aerzte und Studierende 2. Aufl. Leipzig, Veit, 1893

2 Hon EH. Observations on pathological fetal bradycardia. $\mathrm{Am}$ f Obstet Gynecol 1959; 77: 1084.

3 Pardi G, Tucci E, Uderzo Z, Zanini D. Fetal electrocardiogram changes in relation to fetal heart rate patterns during
labour. Am $\mathcal{F}$ Obstet Gynecol 1974; 118: 243-50.

4 Hon EH, Bradfield AH, Hess OW. The electronic evaluation of the fetal heart rate. $V$ The vagal factor in fetal bradycardia. Am $\mathcal{F}$ Obstet Gynecol 1961; 82: 291-300.

5 Yeh M-N, Moroshima HO, Niemann WH, James LS. Myocardial conduction defects in association with comMyocardial conduction defects in association with com-
pression of the umbilical cord. Am $\mathcal{f}$ Obstet Gynecol 1975; pression of the $951-7$.

6 Reeves JT, Daoud FS, Eastin C. Effect of vagotomy on arterial blood pressure and blood gases in the fetal calf. $\mathrm{Am}$ f Physiol 1971; 221: 349.

7 James TN, Sherf L, Fine G, Morales AR. Comparative ultrastructure of the sinus node in man and dog. Circulation 1966; XXXIV: 139-60.

8 Beard RW, Filshie GM, Knight CA, Roberts GM. The significance of the changes in the continuous fetal heart rate in the first stage of labour. F Obstet Gynaecol Br Commonwealth 1971; 78: 865-81.

9 Tipton RF, Finch AJ. The measurement and significance of transient fetal bradycardia during labour. $\mathcal{F}$ Obstet Gynaecol Br Commonwealth. 1972; 79: 133-4.

\title{
Granulocyte colony stimulating factor treatment for neonatal neutropenia
}

\author{
Alison R Bedford Russell, E Graham Davies, Sarah E Ball, Edward Gordon-Smith
}

Department of Child

Health, St George's

Hospital Medical

School, Cranmer

Terrace, London

SW17 ORE

A R Bedford Russell

E G Davies

\section{Department of \\ Haematology \\ $S$ E Ball \\ E Gordon-Smith}

Correspondence to: Dr Bedford Russell.

Accepted 18 August 1994

\begin{abstract}
In a pilot study recombinant human granulocyte colony-stimulating factor (rhG-CSF) was administered to 12 neutropenic preterm infants to determine if neonatal neutropenia is secondary to decreased endogenous G-CSF production. Respiratory variables were monitored because of the possible link between inflammatory cells and hyaline membrane disease. All infants showed increased neutrophil counts. The only possible side effect observed was an exacerbation of thrombocytopenia.

(Arch Dis Child 1995; 72: F53-F54)
\end{abstract}

Keywords: neonatal neutropenia, treatment, rhG-CSF

Neutropenia occurs frequently in preterm infants and, when associated with sepsis, mortality is high. ${ }^{1}$ Recombinant human granulocyte colony stimulating factor (rhG-CSF) induces significant neutrophilia and neutrophil storage pool proliferation in non-neutropenic ${ }^{2}$ and neutropenic ${ }^{3}$ neonates, without toxicity.

The effect of rhG-CSF in 12 critically ill neutropenic neonates was evaluated. Respiratory variables were particularly monitored because inflammatory cells or mediators may be involved in the pathogenesis of hyaline membrane disease and its sequelae. ${ }^{4}$ Pre-treatment G-CSF concentrations were measured to investigate the hypothesis that neonatal neutropenia is secondary to decreased endogenous G-CSF production. ${ }^{5}$

\section{Methods}

RhG-CSF was administered if: (i) absolute neutrophil count (ANC) was $\leqslant 2 \times 10^{9} / 1$ with suspected infection; or (ii) ANC was $\leqslant 1 \times 10^{9} / 1$ and the infant was receiving intensive care. Diagnosis of infection was subsequently confirmed if: a pathogen was cultured from a nor-

Table 1 Details of infants studied showing median (range) of values

\begin{tabular}{lc}
\hline Birth weight (kg) & $0 \cdot 88(0 \cdot 65-2 \cdot 2)$ \\
Gestational age (weeks) & $28(24-35)$ \\
Postnatal age (days) & $3(1-45)$ \\
Days of treatment & $4(1-8)$ \\
Pre-treatment plasma G-CSF (pg/ml) & $3112(60-25000)^{\star}$ \\
\hline
\end{tabular}

${ }^{\star}$ Normal range for adults $<100 \mathrm{pg} / \mathrm{ml}$. 